\title{
Isso é muito bom para ser verdade: mesclagem e subjetividade em construções escalares
}

\author{
Lilian Ferrari e Diogo Pinheiro*
}

\begin{abstract}
Resumo
Este trabalho investiga a Construção Consecutiva Subjetiva Escalar (CCSE), um tipo de construção idiomática formal que apresenta instanciações como "Isso é muito bom para ser verdade" (significando que algo não pode ou não deve ser verdade). O objetivo do trabalho é demonstrar que essa construção gramatical exibe um pareamento forma-significado específico, caracterizando um padrão construcional abstrato do português. Com base em dados reais de uso, e integrando o paradigma da Gramática de Construções à Teoria dos Espaços Mentais (FAUCONNIER, 1994, 1997; FAUCONNIER; TURNER, 2002; SANDERS; SANDERS; SWEETSER, 2009, 2012; FERRARI; SWEETSER, 2012), argumentamos que tal construção (i) ativa um processo de mesclagem conceptual, a partir da compressão de duas escalas análogas e que (ii) indica subjetividade, podendo envolver acesso aos domínios (espaços mentais) epistêmico e de ato de fala.

Palavras-chave: Construção gramatical. Escalaridade. Mesclagem conceptual. Contrafactualidade. Subjetividade.
\end{abstract}

\section{Preliminares}

Desde o trabalho seminal de Fillmore, Kay e O’Connor (1988), o paradigma da Gramática de Construções-GC-tem ressaltado que regras sintáticas gerais e princípios de semântica composicional restringem as possibilidades de uma descrição abrangente da gramática, deixando a descoberto um imenso repositório de "idiomaticidade" cuja descrição não pode ser pautada por tais regras e princípios. Sendo assim, a abordagem construcional tem defendido a existência de um vínculo indissociável entre estrutura sintática e aspectos semânticos/pragmáticos, argumentando que estruturas sintáticas abstratas estão associadas a significados globais, independentes das palavras que as compõem (GOLDBERG, 1995, 2006). Por exemplo, embora apresente itens lexicais

* Universidade Federal do Rio de Janeiro (UFRJ). 
convencionais e sintaxe familiar, a pergunta retórica "Quando foi que eu disse que ia lavar a louça?" não visa a obter como resposta uma data precisa. Trata-se de uma instanciação da construção idiomática [Quando foi que eu disse X?], associada pragmaticamente à inferência de que o falante não pretende lavar a louça. A lista de casos semelhantes é bastante longa. Vejamos alguns exemplos:

(1) O João pagar a conta?! ( $>$ O João não costuma pagar a conta.)

(2) Se o aluno é tão esperto, por que errou a questão? ( $>$ O aluno não é esperto.)

(3) O que é que ele está fazendo em cima do telhado? ( $>$ Ele não deveria estar em cima do telhado.)

(4) Partiu praia! (> Convite/sugestão para ir à praia.)

Adotando a perspectiva teórica da GC, este trabalho investiga um tipo de construção idiomática formal que pode apresentar instanciações do seguinte tipo: ${ }^{1}$

(5) Ele está muito doente para ser mandado aos Estados Unidos (...). ${ }^{2}$

(6) [...] a companhia aérea British Airways afirmou que o jovem era gordo demais para voar em uma de suas aeronaves. ${ }^{3}$

Os exemplos (5) e (6) ilustram uma construção de causa e efeito na qual o efeito inverte a polaridade do estado de coisas introduzido pela preposição "para". Em termos pragmáticos, a construção autoriza a inferência de que o evento apresentado na subordinada não pode/deve ocorrer. Assim, em (5), depreende-se que "ele não pode/deve ser mandado aos Estados Unidos"; em (6), a inferência é a de que o falante considera que "o jovem não pode/deve voar em nossas aeronaves".

Do ponto de vista sintático, a oração nuclear [(X) V \{INTENS.\} ADJ] ("ele está muito doente"; "o senhor é gordo demais") envolve um verbo flexionado, ${ }^{4}$ um adjetivo e um intensificador (muito, demais, excessivamente, etc.), ${ }^{5}$ que pode ocorrer antes ou depois do adjetivo. A oração [PARA INF (Y)], apresenta verbo no infinitivo e seu complemento (Y), se for o caso. Por razões que ficarão claras no decorrer do artigo, essa construção será aqui denominada Construção Consecutiva Subjetiva Escalar (CCSE). ${ }^{6}$

1 Todos os exemplos de uso real foram localizados por meio do mecanismo de busca Google. Para cada exemplo desse tipo, os links serão disponibilizados em nota de rodapé.

2 Disponível em: <http://www.cpr.org.br/ser-dizimista-nao.htm>. Acesso em: 9 set. 2011.

3 Disponível em: <http://veja.abril.com.br/noticia/economia/british-airways-rejeita-passageiro-porser-gordo-demais $>$. Acesso em: 7 nov. 2013.

4 Naturalmente, o verbo pode aparecer em forma finita caso a oração em que ele ocorre esteja encaixada em uma oração matriz sem complementizador; por exemplo: "Ele acredita estar muito doente para ser mandado aos Estados Unidos.". Neste trabalho, porém, restringimo-nos aos usos com verbo não finito. $5 \mathrm{O}$ intensificador aparece entre chaves para indicar que sua posição não é fixa.

6 Certamente, existe uma família de construções intimamente relacionadas à CCSE. Estamos nos 
Embora ausentes das gramáticas de referência tradicionais (ROCHA LIMA, 1972; BECHARA, 1999; CUNHA; CINTRA, 2001), usos como (5) e (6) são contemplados em obras como Neves (2000), Mateus et al. (2003) e Azeredo (2011). Em todos esses casos, a cláusula infinitiva da CCSE é tratada como um enunciado de valor consecutivo. Por exemplo, Neves inclui o uso em (7a) entre as “construções consecutivas": (NEVES, 2000, p. 920).

(7a) São Tomás de Aquino tinha uma genialidade filosófica muito grande para limitar-se simplesmente a seguir fielmente o aristotelismo.

O que justifica essa inclusão é, presumivelmente, o fato de que a impossibilidade de São Tomás de Aquino limitar-se a seguir fielmente o aristotelismo é construída semanticamente como algo que decorre da genialidade do filósofo. É possível enxergar aí, portanto, uma relação de causa e efeito, que poderia ser expressa sob a forma de uma consecutiva canônica como (7b):

(7b) São Tomás de Aquino tinha uma genialidade filosófica tão grande que não poderia limitar-se simplesmente a seguir fielmente o aristotelismo.

A autora não chega, entretanto, a discutir as peculiaridades da construção instanciada por (7a). Uma primeira pista para elucidar essa especificidade pode ser encontrada em Azeredo (2011), para quem, em usos como (8), “o efeito, indicado pela preposição para, é objeto de censura ou de estranheza do enunciador, que, na realidade, faz um comentário, que pode ser parafraseado como conclusão" (AZEREDO, 2011, p. 328).

(8) Você já está bem grandinho para precisar de babá.

Embora a caracterização proposta por Azeredo forneça um ponto de partida interessante e profícuo para a compreensão desse uso, parece claro que a CCSE ainda se ressente de análises mais detalhadas, que investiguem e sistematizem suas especificidades semânticas e pragmáticas. Com este trabalho, pretendemos contribuir para preencher essa lacuna. Para isso, recorremos ao instrumental teórico da Linguística Cognitiva, com ênfase sobre os seguintes modelos de análise: a proposta de Coulson (2001) para o tratamento das construções contrafactuais escalares à luz da Teoria da Mesclagem Conceptual e o tratamento da subjetividade à luz da Teoria dos Espaços Mentais (SANDERS; SANDERS; SWEETSER, 2009, 2012; FERRARI; SWEETSER, 2012).

referindo aqui a usos que expressam suficiência (em vez de excesso), como "Ele está saudável o suficiente para ser mandado aos Estados Unidos.", bem como a usos em que o intensificador se vincula diretamente ao predicador verbal (e não ao adjetivo), como em "Ele se esforçou demais para ser tão maltratado assim.”. Apesar do parentesco, essas estruturas não serão tratadas neste artigo. 
A hipótese central do trabalho é a de que a CCSE, ilustrada em (5), (6), (7a) e (8) se caracteriza por indicar: (i) mesclagem escalar (COULSON, 2001), e (ii) subjetividade (SANDERS; SANDERS; SWEETSER, 2009, 2012; FERRARI; SWEETSER, 2012). O artigo está organizado em três seções principais. Na próxima seção, apresentamos os modelos teóricos que fundamentam nossa análise. Na sequência, as duas seções seguintes investigam, respectivamente, a construção da semântica contrafactual da construção e seu caráter subjetivo.

\section{Aporte teórico}

\subsection{Mesclagem e contrafactualidade}

Coulson (2001) argumenta que construções contrafactuais sempre envolvem mesclagem conceptual entre o estado de coisas vigente e informações genéricas provenientes de outro(s) inputs. A autora ilustra esse fenômeno a partir de uma situação em que alguém abre a geladeira e diz:

(9) Se tivesse pão, eu poderia fazer um sanduíche.

O processo de mesclagem ativado pela condicional acima envolve o espaço Base, que corresponde à situação real, um espaço associado ao frame genérico de sanduíche e o espaço-mescla, que reúne elementos provenientes dos dois espaços anteriores. Vejamos

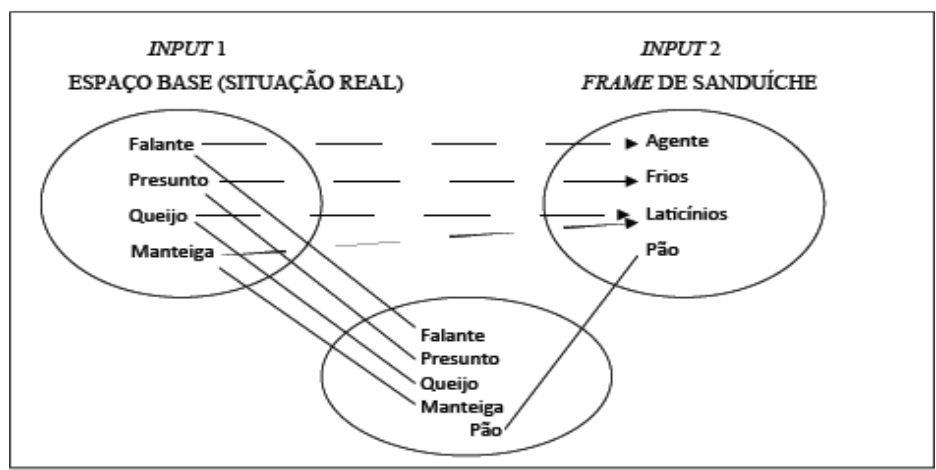

Diagrama 1 - Mesclagem conceptual referente ao exemplo (9)

Espaço-mescla contrafactual 
O diagrama acima ilustra a criação de um espaço contrafactual a partir de elementos projetados da situação real (falante, presunto, queijo, manteiga) e de um elemento projetado do frame genérico de sanduíche (pão). Na mescla, o falante dispõe não só dos ingredientes existentes na situação real, mas também do ingrediente ausente na situação (no caso, o pão).

Quanto aos tipos de contrafactuais e suas motivações, Turner (1996) propôs a seguinte subdivisão:

a) Contrafactuais de laboratório ("lab rats counterfactuals") - são aquelas em que todas as propriedades do mundo real se mantêm no mundo contrafactual, exceto uma propriedade que é conectada a um resultado particular. O objetivo é predizer um determinado estado de coisas. Ex.: Se este fósforo tivesse sido riscado, ele teria acendido.

b) Contrafactuais de holofote ("spotlight counterfactuals") - são aquelas que lançam luz sobre algum aspecto do mundo real. O objetivo é retórico. Ex.: $\mathrm{Na}$ França, Watergate não teria prejudicado Nixon.

Dentre essas últimas, Coulson (2001, p. 215) chama a atenção para um tipo especial, as contrafactuais escalares. Essas contrafactuais envolvem inferências a partir de uma escala pragmática, que apresenta objetos ou cenários ordenados ao longo de uma determinada dimensão semântica. Como exemplos, a autora menciona construções do tipo "Toni não consegue correr cinco quilômetros, quanto mais dez" e "Eu não sairia com você nem que você fosse o último homem na face da Terra". ${ }^{7}$

No presente trabalho, defendemos que há um subtipo de construção consecutiva que se caracteriza por promover inferências de contrafactualidade a partir do processo de mesclagem escalar. É o que será detalhado na seção 3.1.

\subsection{Espaços mentais e subjetividade}

No âmbito da Linguística Cognitiva, o tratamento clássico e pioneiro da subjetividade na gramática é aquele proposto por Langacker (1990) à luz da sua Cognitve Grammar. Para esse autor, o grau de subjetividade ou objetividade de um determinado uso linguístico está relacionado ao maior ou menor perfilamento

7 Os exemplos originais em inglês são: “Tony can't run five kilometers, much less ten" e "I wouldn’t go out with you if you were the last man on earth". 
do ground, conceito que abrange o "evento de fala, seus participantes e suas circunstâncias imediatas". (LANGACKER, 1991, p. 548).

Mais recentemente, a questão da subjetividade tem sido retomada e reinterpretada no âmbito da Teoria dos Espaços Mentais - TEM. Desenvolvida originalmente por Fauconnier (1994; 1997) para dar conta de problemas clássicos de referenciação, a TEM assume que o processamento do fluxo discursivo se inicia em um espaço mental conhecido como Espaço Base, normalmente identificado ao aqui e agora interacional e definido como uma espécie de âncora do discurso. ${ }^{8}$

Neste artigo, recorremos a uma versão mais recente da TEM, que será denominada versão BCSN (por razões que ficarão mais claras adiante) e que tem sido desenvolvida por autores como Sanders, Sanders e Sweetser $(2009$; 2012) e Ferrari e Sweetser (2012). Em relação ao modelo original, as inovações trazidas pela versão BCSN decorrem de dois insights fundamentais. O primeiro diz respeito à necessidade de estabelecer uma separação entre o ato de interação em si mesmo e o conteúdo efetivamente comunicado. Na versão original da TEM, o Espaço Base pode funcionar, ao mesmo tempo, como o "lugar" onde estão os interlocutores, sujeitos de comunicação e conceptualização, e o espaço onde estão certos objetos comunicados e conceptualizados por meio do discurso. Como se trata de planos qualitativamente distintos, a versão BCSN busca distingui-los claramente: de um lado, está o ground comunicativo (FERRARI; SWEETSER, 2012) ou Centro Dêitico da Comunicação (SANDERS; SANDERS; SWEETSER, 2009; 2012), que corresponde ao aqui e agora interacional; de outro, o Domínio do Conteúdo - DC -, plano do conteúdo efetivamente comunicado/conceptualizado.

O segundo ponto fundamental é a ideia de que o self não é unificado, mas heterogêneo. Dito informalmente, os interlocutores são, ao mesmo tempo, pessoas físicas localizadas em um determinado espaço-tempo real, sujeitos que executam atos de fala e seres pensantes dotados de estados mentais e capazes de desenvolver processos de raciocínio. Assim, na versão BCSN, cada faceta dos interlocutores é representada em um espaço mental distinto, todos eles integrantes do ground. As facetas mencionadas acima correspondem aos seguintes espaços: Espaço Real (falante e ouvinte como pessoas físicas, no tempo e espaço reais da interação),

8 Por essa razão, o Espaço Base pode ser relacionado ao ground langackeriano. Tal aproximação, porém, demanda cautela. Embora as duas noções se aproximem quando se trata da interação face a face, elas tendem a se distanciar em outros contextos. Por exemplo, em uma narrativa escrita, o ground corresponde ao momento/local em que o escritor realiza seu trabalho, enquanto o espaço Base pode corresponder ao momento/local em que a estória tem início. 
Espaço de Ato de Fala (falante e ouvinte como interlocutores engajados em uma ação linguística conjunta/intersubjetiva) e Espaço Epistêmico (falante e ouvinte como sujeitos cognitivos, dotados de estados/processos mentais).

Para além desses três espaços, dois outros têm sido citados como integrantes da rede de espaços mentais que compõem o ground: um Espaço Metalinguístico, que inclui um conjunto de pareamentos forma/significado, e um Espaço Metatextual, que registra o histórico da conversação. A figura abaixo, adaptada de Ferrari e Sweetser (2012), representa visualmente essa proposta:

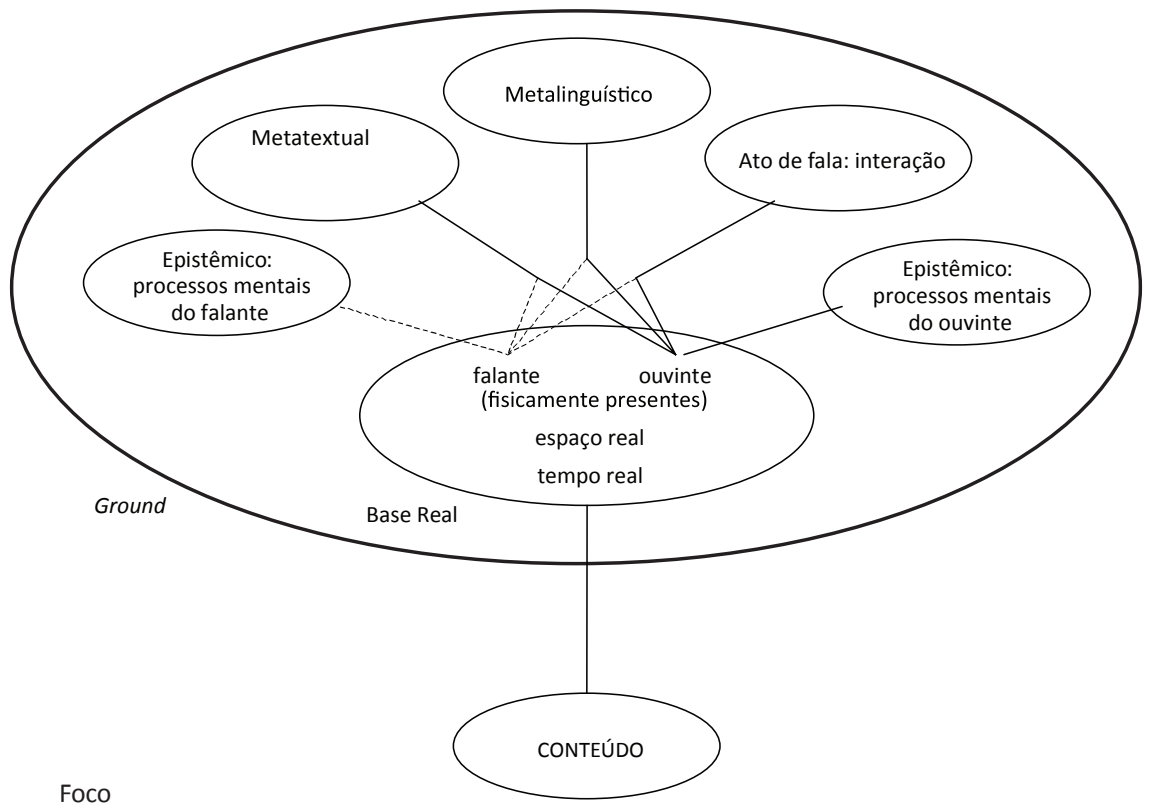

Diagrama 2 - Basic Communicative Spaces Network (BSCN)

Partindo desse modelo, Ferrari e Sweetser (2012) se propõem a formalizar o insight langackeriano segundo o qual subjetividade na linguagem significa referência implícita ao ground comunicativo. Para Langacker, um uso como "amanhã deve chover" é subjetivo porque evoca o ground (deve ser entendido como uma conclusão do falante), mas o faz implicitamente (não há referência explícita ao falante). Nos termos do modelo BCSN, isso significa que, quanto maior o grau de subjetividade de uma construção, mais o seu significado convencional dependerá de informações 
disponíveis no ground, que deverão ser acessadas para a interpretação do enunciado. Por outro lado, como o ground não é entendido como uma estrutura homogênea, mesmo em seu interior existem espaços mais e menos subjetivos. Aqui, o critério de diferenciação é o grau de verificabilidade intersubjetiva das informações relativas a cada espaço. Por convenção, os espaços mais subjetivos - aqueles que são menos verificáveis intersubjetivamente - são representados nos pontos mais altos da rede (FERRARI; SWEETSER, 2012). Assim, usos que fazem referência à Base Real seriam menos subjetivos do que aqueles que evocam implicitamente o Espaço Epistêmico ou o Espaço de Ato de Fala. Nesse sentido, a mudança semântica conhecida como subjetificação é entendida como uma operação conceptual de projeção para cima ("upward projection"). ${ }^{9}$ Neste artigo, procuraremos mostrar que a CCSE é fortemente subjetiva na medida em que não apenas faz referência implícita ao ground como demanda acesso a informações localizadas em dois dos espaços mais altos na rede de espaços comunicativos básicos: o Espaço Epistêmico e o Espaço de Ato de Fala.

\section{A Construção Consecutiva Subjetiva Escalar: especificações semântico- -pragmáticas}

Neste momento, passamos a uma análise sistemática das particularidades semânticas e pragmáticas da CCSE. Duas propriedades da construção serão contempladas: na seção 3.1, mostraremos que ela dispara um processo cognitivo de mesclagem escalar; em seguida, na seção 3.2, evidenciamos o caráter subjetivo da construção, nos termos da Teoria dos Espaços Mentais.

\subsection{A contrafactualidade na Construção Consecutiva Subjetiva Escalar}

Nesta seção, objetivamos demonstrar que a CCSE indica mesclagem conceptual, a partir da compressão de duas escalas análogas. Além disso, com base na proposta de

9 As autoras utilizam a noção de "upward projection" para explicar casos clássicos de gramaticalização/ subjetificação, como o desenvolvimento do artigo definido "the", associado à Base Real, a partir de determinantes dêiticos, associados ao Espaço de Ato de Fala. Note-se que essa mudança semântica envolve, precisamente, uma projeção conceptual que parte de um espaço mais baixo em direção a outro mais alto na rede de espaços mentais. 
Coulson (2001), sugerimos que a construção é um subtipo de contrafactual escalar, na medida em que o estado de coisas apontado na estrutura subordinada [para INF $(\mathrm{Y})$ ] deve ser entendido como "contrário às expectativas e/ou crenças" do falante. ${ }^{10}$

Com relação ao primeiro objetivo, defendemos que a construção não deve ser interpretada composicionalmente, mas funciona como uma instrução para promover integração conceptual entre dois espaços mentais. O primeiro é ativado pela oração matriz e diz respeito a uma avaliação escalar da situação em curso; o segundo envolve a avaliação de um evento genérico segundo a mesma escala. Na mescla, as escalas são comprimidas em uma única escala contendo os elementos $\mathrm{X}$, do Input 1, e sua contraparte X', do Input 2, dispostos em posições específicas. A estrutura emergente autoriza inferências resultantes exatamente da distância observada entre essas duas posições.

Observemos alguns exemplos:

(10) Ana é muito jovem para se casar. (> ela não pode/deve se casar)

(11) Está muito frio para fazer exercícios ao ar livre. (> não quero/posso/devo fazer exercícios ao ar livre)

(12) Isso é muito bom para ser verdade. ( $>$ isso não pode/deve ser verdade)

Tomando o exemplo (10) para ilustrar o processo de mesclagem ativado pela Construção Consecutiva Subjetiva Escalar, apresentamos o seguinte diagrama:

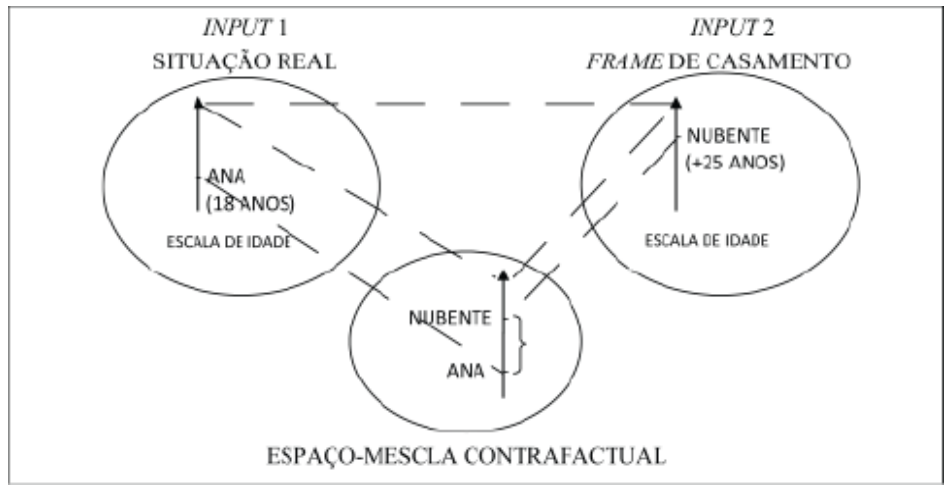

Diagrama 3 - Processo de mesclagem escalar referente ao exemplo (10)

10 Essa definição afasta-se da definição tradicional de contrafactualidade, que diz respeito a marcas linguísticas convencionais para indicar eventos como "contrários aos fatos". Respaldando-nos na proposta de Dancygier e Sweetser (2005, p.71), que advogam que a contrafactualidade também pode resultar de inferências ativadas em contexto por estruturas linguísticas não convencionalmente contrafactuais, e levando em conta a questão da subjetividade, achamos pertinente estender a noção para incluir estruturas linguísticas que ativam inferências relacionadas a eventos "contrários às expectativas e/ou crenças do falante". 
No diagrama acima, o input 1 dispõe a idade de Ana, 18 anos, em uma escala relativa à faixa etária. $\mathrm{O}$ input 2 organiza-se a partir de um frame de casamento, com a nubente disposta em uma escala de idade apropriada para casar (acima de 25 anos). As duas escalas, por serem escalas de idade, são projetadas e comprimidas em uma única escala no espaço mescla. Ana e a nubente são projetadas nessa escala, mantendo as posições em que estavam nas escalas originais. Na mescla, é possível observar um hiato entre a idade de Ana e a idade da nubente ideal. A estrutura emergente permite a inferência de que Ana não tem idade apropriada para se casar. $\mathrm{O}$ efeito retórico da construção pode ser o de criticar, lamentar ou mesmo proibir o casamento de Ana, dependendo do tipo de autoridade exercida pelo falante.

A proposta de que a leitura desse tipo de construção não é composicional pode ser reforçada, ainda, a partir do contraste entre as seguintes construções:

(13) Ana é muito jovem para se casar.

(14) Ana é muito jovem para se aposentar.

Enquanto, em (13), Ana deve ter menos do que 25 anos (considerando-se essa a idade ideal para o casamento), em (14) Ana deve ser bem mais velha. A sentença pode ser usada para indicar alguém de 55 anos que já tenha direito legal de se aposentar, mas que se mostre ainda bastante ativa e dinâmica. Isso indica que o sintagma adjetival "muito jovem" não deve ser interpretado isoladamente, mas sua interpretação dependerá do papel que desempenha na mescla.

\subsection{A subjetividade na Construção Consecutiva Subjetiva Escalar}

Como tem sido demonstrado em outros estudos que se debruçam sobre construções de causa e efeito (SANDERS; SANDERS; SWEETSER, 2009, 2012), os marcadores de causalidade podem exibir diferentes graus de subjetividade. Fundamentalmente, é possível que o nexo causal seja construído como uma relação criada por um determinado sujeito cognoscente ou como uma relação objetiva entre eventos do mundo (sem interferência, portanto, do sujeito cognoscente). Nesta seção, procuraremos mostrar que as relações de causa e efeito expressas por meio da CCSE são do primeiro tipo. Nesse sentido, argumentaremos que uma propriedade importante dessa construção, ao lado da expressão de contrafactualidade escalar, reside no seu caráter eminentemente subjetivo. 
Uma evidência desse caráter subjetivo é o fato de que a CCSE constrói a relação causal no domínio da potencialidade: em vez de representar uma conexão intrínseca entre dois eventos, ela exprime a avaliação de um sujeito acerca de um evento potencial. É precisamente por isso que, em contraste com o que ocorre com as consecutivas canônicas, o conteúdo da CCSE pode ser negado sem que se produza uma contradição, como se vê na comparação entre os exemplos abaixo:

(15a)\# O João estava tão cansado que dormiu na hora, mas não dormiu na hora.

(15b)O João estava cansado demais para ficar acordado, mas (ainda assim) ficou acordado.

Em (15a), o enunciado constrói a relação causal (entre "estar muito cansado" e "dormir na hora") como concreta; por isso, afirmar a ocorrência da consequência para negá-la em seguida acarreta uma contradição, resultando em um enunciado pragmaticamente malsucedido. Em (15b), por outro lado, a CCSE exprime uma avaliação quanto à improbabilidade do evento, e não uma afirmação categórica de sua não ocorrência; por isso, a enunciação da sentença adversativa não produz uma contradição. ${ }^{11}$ Como vimos na seção anterior, essa avaliação é o resultado de uma mesclagem de dois tipos de informações: conhecimento de mundo geral (a partir de que grau de cansaço alguém se torna incapaz de se manter acordado) e informações disponíveis sobre a situação específica em pauta (o quão cansado João estava naquele momento).

Como já ficou dito, entendemos subjetividade como referência implícita ao ground comunicativo. Por um lado, a CCSE envolve referência ao ground na medida em que sua interpretação da CCSE inclui a ideia de uma avaliação por parte de um sujeito cognoscente. Em (15b), por exemplo, não se trata simplesmente de afirmar que o evento "dormir na hora" foi causado pelo evento "estar muito cansado". Trata-se, a rigor, de expressar a ideia de que um determinado sujeito cognoscente (o falante) julgou o evento "dormir na hora" como decorrência provável ou esperada do evento "estar muito cansado", a partir de um cruzamento do seu conhecimento de mundo geral e específico. É nesse sentido que a relação de causa e efeito expressa por (15b) não se constitui como um nexo causal inerente ou objetivo, mas como uma construção subjetiva.

11 Isso não significa que consecutivas canônicas não possam exprimir potencialidade; significa apenas que o domínio da potencialidade é parte inerente da semântica da CCSE, diferentemente do que ocorre com a construção consecutiva canônica. 
Por outro lado, a referência ao ground é implícita porque a codificação linguística não envolve formulações como "eu suponho/avalio que ele não ficará acordado". Isso significa que o caráter de avaliação de um evento potencial, embora seja parte fundamental da semântica da CCSE, não fica manifesto de forma explícita.

Neste ponto, é necessário enfrentar a seguinte questão: quem é o sujeito cognoscente responsável pela avaliação presente na semântica da CCSE? A abordagem langackeriana associa a subjetividade a uma maior visibilidade do aqui e agora da interação; no entanto, a abordagem baseada em espaços mentais tem revelado que usos subjetivos podem evocar a subjetividade de outros indivíduos para além dos interlocutores (SANDERS; SANDERS; SWEETSER, 2009, 2012; SWEETSER, 2012). Como nota Sweetser (2012, p. 6), "a linguagem também pode expressar o que participantes imaginados podem alcançar, tocar, perceber, saber, pensar, pressupor, calcular e sentir em relação a espaços relevantes - e não apenas o que o falantes e ouvintes presentes podem estar cognizando" (destaque no original). Com efeito, a investigação da CCSE mostrou que o sujeito evocado nas relações causais nem sempre coincide com o falante/escritor. Vejamos:

(16) Eu acho que as empresas estão grandes demais para serem conduzidas. Especialmente, são grandes demais para serem inovativas. ${ }^{12}$

(17) É tarde demais para Sarney ter uma boa ideia, mas ele teve uma boa ideia. ${ }^{13}$

(18) Os advogados de Gary McKinnon, 43, argumentam na Alta Corte de Londres que ele está muito doente para ser mandado aos Estados Unidos para ser julgado por ter a síndrome de Asperger, uma forma de autismo. ${ }^{14}$

(19) Condenado por duplo homicídio, Richard Cooey, 1,70 metro, $121 \mathrm{~kg}$ (IMC 41, obesidade mórbida), pediu clemência alegando que é pesado demais para receber o único método de execução autorizado no estado de Ohio, a injeção letal. ${ }^{15}$

Nos exemplos acima, apenas em (16) e (17) o sujeito responsável pela construção da relação causal é enunciador; os usos em (18) e (19) mostram que a CCSE pode fazer referência a subjetividades alternativas, disponíveis textualmente

12 Disponível em: <http://agencia.fapesp.br/14364>. Acesso em: 3 out. 2013.

13 Disponível em: <http://veja.abril.com.br/blog/reinaldo/geral/e-tarde-demais-para-sarney-ter-umaboa-ideia-mas-ele-teve-uma-boa-ideia $>$. Acesso em: 9 set. 2011.

14 Disponível em: $<$ http://www.cpr.org.br/ser-dizimista-nao.htm>. Acesso em: 9 set. 2011.

15 Disponível em: <http://scienceblogs.com.br/cretinas/2008/08/gordo-demais-para-morrer/>. Acesso em: 9 set. 2013. 
e evocadas, aqui, via discurso indireto. O que esses últimos exemplos sugerem é a existência de BCSNs recursivas: cada interlocutor conta com a sua rede, mas, para além disso, os sujeitos referidos no discurso também são dotados de uma subjetividade própria, dispondo, assim, de sua própria rede de espaços mentais. Essa configuração representa situações em que, como em (18) e (19), o conteúdo do enunciado não diz respeito diretamente à subjetividade do falante/escritor, mas à subjetividade de uma terceira pessoa. ${ }^{16}$

Até aqui, temos o seguinte quadro: a CCSE evoca implicitamente o ground de um sujeito cognoscente, que pode ou não coincidir com o falante/escritor. Neste ponto, a pergunta que se coloca é a seguinte: especificamente, qual espaço mental do ground a CCSE evoca implicitamente? Aqui, argumentamos que essa construção faz referência a dois espaços mentais mais altos - e, portanto, mais subjetivos - que a Base Real: o Espaço Epistêmico e Espaço de Ato de Fala. No primeiro caso, o enunciado traduz uma previsão acerca da probabilidade de ocorrência do evento expresso pela CCSE; no segundo, trata-se de um ato de fala diretivo (conselho, pedido, ordem, etc.) que reflete um julgamento acerca da importância/necessidade de realização do evento.

Os exemplos acima atestam essas duas possibilidades, evidenciando a ambiguidade sistemática da CCSE. Nos dois primeiros casos, a relação causal é construída no plano epistêmico: os falantes/escritores não estão sugerindo ou ordenando que as empresas se tornem ingovernáveis e burocráticas (no primeiro caso) ou que o Sarney evite as boas ideias (no segundo). Trata-se, em vez disso, de fazer previsões que emergem como decorrências de premissas específicas: dado que as empresas estão excessivamente inchadas, prevê-se que será improvável ou impossível administrá-las ou mantê-las "inovativas"; dado que Sarney não é conhecido por ter boas ideias, não se espera que, a uma certa altura da vida, ele ainda tenha uma boa ideia. Nesse sentido, o conteúdo da cláusula matriz é enquadrado conceptualmente como fundamento da previsão apresentada. Nos termos do modelo BCSN, interpretar (16) e (17) demanda o acesso ao Espaço Epistêmico do sujeito responsável pela avaliação - o espaço onde estão representados seus processos de raciocínio.

16 Sanders, Sanders e Sweetser $(2009,2012)$ desenvolvem com alguma minúcia esse ponto em seu estudo sobre os conectivos causais em holandês, explorando os casos de discurso indireto e discurso indireto livre. Os autores defendem explicitamente que "não é apenas o Falante que tem seu próprio Espaço Mental; potencialmente, todos os Sujeitos de Consciência o têm" (SANDERS; SANDERS; SWEETSER, 2009, p. 52). 
O caso de (18) e (19) é um pouco diferente, na medida em que a relação causal se atualiza no domínio sociopragmático. Em (18), nota-se que o papel de sujeito avaliador cabe aos "advogados de Gary McKinnon". Como a forma verbal "argumentam" sugere, não se trata aqui de prever que o cliente não será deportado, mas de solicitar ou defender a não deportação. A inferência produzida, portanto, não é a de que o evento de enviar o réu aos EUA provavelmente não irá ocorrer, e sim a de que a Corte não deveria autorizar ou exigir que o evento ocorresse. Nesse sentido, o conteúdo da cláusula matriz é enquadrado conceptualmente como fundamento para a solicitação apresentada: o fato de Gary McKinnon estar doente justifica e embasa o pedido de não deportação. Nos termos do modelo BCSN, o enunciado proferido implica acesso não ao Espaço Epistêmico (que envolve uma avaliação de probabilidade/possibilidade), mas ao Espaço de Ato de Fala (que envolve ações verbais como proibição, conselho, recomendação, censura, etc.).

Caso análogo é o de (19). Também aqui, a inferência produzida pela CCSE não é enquadrada como uma previsão; em vez disso, o acesso a elementos da situação comunicativa deixa claro que se trata de algo como um pedido ou súplica. Desse modo, tanto em (18) quanto em (19) o espaço mental relevante para a interpretação do enunciado é o Espaço de Ato de Fala.

Interessantemente, e de maneira análoga ao que acontece notoriamente com os verbos modais, é possível que um mesmo enunciado admita as leituras epistêmica e de ato de fala. Vejamos o caso de (20):

(20) Daniel Alves afirmou nesta terça-feira que "a seleção brasileira é algo muito grande para Neymar carregar sozinho". ${ }^{17}$

$\mathrm{Na}$ ausência de informações adicionais, a fala atribuída a Daniel Alves pode ser interpretada de duas maneiras: (i) Neymar provavelmente não conseguirá carregar a seleção brasileira sozinho, e (ii) não se deve exigir que Neymar carregue a seleção brasileira sozinho. No primeiro caso, a interpretação do enunciado envolve acesso ao Espaço Epistêmico, de maneira que seu conteúdo é enquadrado como previsão; no segundo, faz-se referência implícita ao Espaço de Ato de Fala, produzindo-se a especificação pragmática de conselho, recomendação. As duas possibilidades estão representadas no diagrama a seguir: ${ }^{18}$

17 Disponível em: <http://www1.folha.uol.com.br/esporte/folhanacopa/2013/06/1289568-selecao-emuito-grande-para-neymar-carregar-sozinho-diz-daniel-alves.shtml >. Acesso em: 27 out. 2013.

18 Em nome da clareza visual, representamos apenas os espaços mentais diretamente relevantes para a CCSE. 


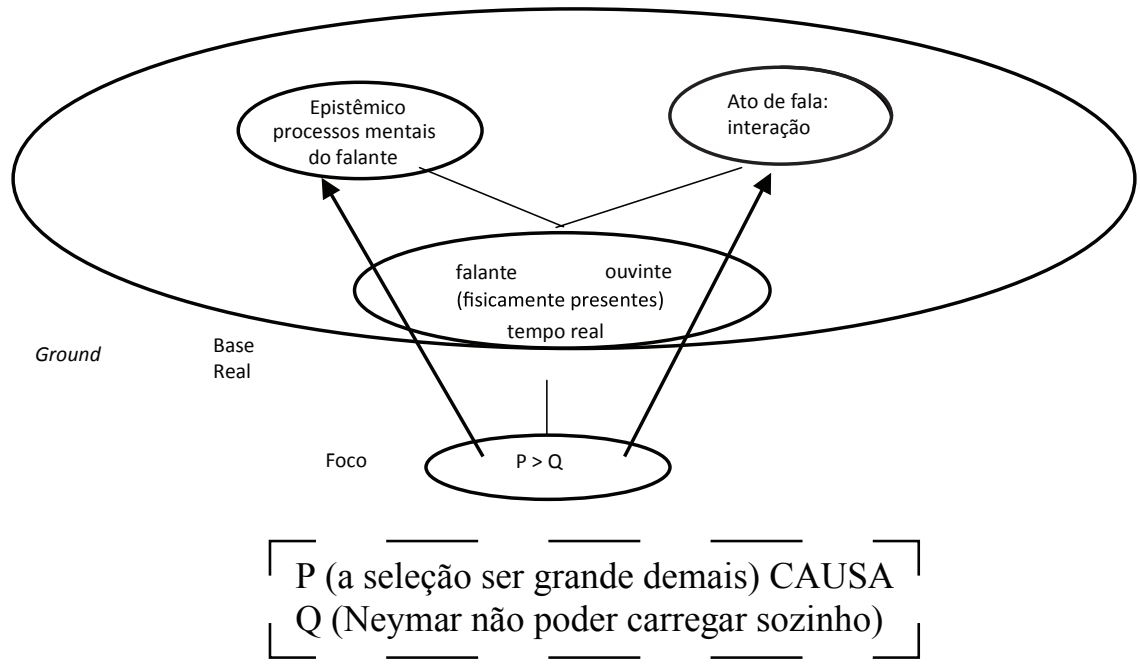

Diagrama 4 - Ambiguidade na construção da relação causal subjetiva em (20)

Temos, em suma, o seguinte quadro: em se tratando da CCSE, o nexo causal é sempre construído como uma relação criada por um sujeito cognoscente que pode ou não coincidir com o falante/escritor (e não como relação objetiva e inerente a eventos do mundo). Esse sujeito, porém, não é explicitado linguisticamente. Por isso, nos termos do modelo BCSN, diremos que a CCSE ativa referência implícita ao ground comunicativo, caracterizando-a como uma construção subjetiva. Para além disso, observamos que a relação causal evoca, especificamente, dois dos espaços mais altos - portanto, mais subjetivos - do ground comunicativo: o Espaço Epistêmico (a causalidade é construída como resultado de uma ação mental/psicológica) e o Espaço de Ato de Fala (a causalidade envolve uma ação social/intersubjetiva).

\section{Considerações finais}

Em suma, procuramos neste trabalho demonstrar que a CCSE: (i) indica mesclagem conceptual, a partir da compressão de duas escalas análogas; (ii) é um subtipo de contrafactual escalar, nos termos de Coulson (2001); (iii) é subjetiva, 
na medida em que constrói o nexo causal como uma relação construída por um sujeito de consciência, assim evocando implicitamente o ground comunicativo; e (iv) faz referência, na BCSN, ao Espaço Epistêmico ou ao Espaço de Ato de Fala, podendo apresentar, portanto, uma ambiguidade sistemática entre dois domínios semânticos: o epistêmico (processos mentais) e o deôntico (sociopragmático).

\title{
This is too good to be true: blending and subjectivity in scalar constructions
}

\begin{abstract}
This paper investigates a complex formal idiom in Brazilian Portuguese, consisting of a main clause and its subordinate clause introduced by the preposition PARA. This formal structure can be instantiated by sentences like "Isso é muito bom para ser verdade" (roughly, "This is too good to be true"). Semantically, the construction causally correlates some entity's intensified quality (e.g. too good) with specific states of affairs (e.g. to be true), giving rise to inferences of counterfactuality (i.e., "this cannot/ might not be true"). Drawing on Construction Grammar and Mental Spaces Theory (FAUCONNIER, 1994, 1997; FAUCONNIER; TURNER, 2002), we argue that this construction presents form-meaning pairings which: (i) prompt for scalar blending, by compressing two analogous scales into one, and (ii) indicate subjectivity, implicitly referring to epistemic or speech act spaces in the Basic Communicative Spaces Network (SANDERS; SANDERS; SWEETSER, 2009, 2012; FERRARI; SWEETSER, 2012).

Keywords: Grammatical construction. Scalarity. Conceptual blending. Counterfactuality. Subjectivity.
\end{abstract}

Referências

AZEREDO, José Carlos de. Gramática Houaiss da Língua Portuguesa. São Paulo: Publifolha, 2011.

BECHARA, Evanildo. Moderna gramática portuguesa. Rio de Janeiro: Lucerna, 1999. 
COULSON, Seana. Semantic Leaps: frame-shifting and conceptual blending in meaning construction. Cambridge: Cambridge University Press, 2001.

CUNHA, Celso; CINTRA, Lindley. Nova gramática do português contemporâneo. Rio de Janeiro: Nova Fronteira, 2001.

FAUCONNIER, Gilles. Mental spaces: aspects of meaning construction in natural language. Cambridge: Cambridge University Press, 1994. Original publicado em 1985.

FAUCONNIER, Gilles. Mappings in thought and language. Cambridge: University Press, 1997.

FAUCONNIER, Gilles; TURNER, Mark. The way we think: conceptual blending and the mind's hidden complexities. New York: Basic Books, 2002.

FERRARI, Lilian; SWEETSER, Eve. Subjectivity and upwards projection in mental space structure. In: DANCYGIER, Barbara; SWEETSER, Eve (Org.). Viewpoint in language: a multimodal perspective. Cambridge: Cambridge University Press, 2012.

FILLMORE, Charles J.; KAY, Paul; O'CONNOR, Mary Catherine. Regularity and idiomaticity in grammatical constructions: the case of let alone. Language, v. 64, n. 3, p. 501-38, Sep. 1988.

GOLDBERG, Adele E. Constructions: a construction grammar approach to argument structure. Chicago: University Press, 1995.

GOLDBERG, Adele E. Constructions at work: the nature of generalization in language. Cambridge: University Press, 2006.

LANGACKER, Ronald W. Subjectification. Cognitive Linguistics, v. 1, p. 5-38, 1990.

LANGACKER, Ronald W. Foundations of cognitive grammar: descriptive applications. Stanford, CA: Stanford University Press, 1991.

NEVES, Maria Helena de Moura. Gramática de usos do português. São Paulo: Editora Unesp, 2000.

MATEUS, Maria Helena Mira; BRITO, Ana Maria; DUARTE, Inês; FARIA, Isabel Hub; FROTA, Sônia; MATOS, Gabriela; OLIVEIRA, Fátima; VIGÁRIO, Marina;, VILLALVA, Alina. Gramática da língua portuguesa. Lisboa: Caminho, 2003.

ROCHA LIMA, Carlos Henrique da. Gramática normativa da língua portuguesa. Rio de Janeiro: José Olympio, 1992. 
SANDERS, Ted; SANDERS, Jose; SWEETSER, Eve. Causality, cognition and communication: a mental space analysis of subjectivity in causal connectives. In: SANDERS, Ted; SWEETSER, Eve (Org.). Causal categories in discourse and cognition. Berlin/New York: Mouton de Gruyter, 2009.

SANDERS, Ted; SANDERS, Jose; SWEETSER, Eve. Responsible subjects and discourse causality: how mental spaces and perspective help identifying subjectivity in Dutch backwards causal connectives. Journal of pragmatics, v. 44, p. 191-213, 2012.

SWEETSER, Eve. Introduction: viewpoint and perspective in language and gesture, from de Ground down. In: DANCYGIER, Barbara; SWEETSER, Eve (Org.). Viewpoint in language: a multimodal perspective. Cambridge: Cambridge University Press, 2012. 